\title{
Estudo de diferentes doses de furosemida sobre a função renal de bovinos hígidos
}

\author{
Study of different doses of furosemide on the urinary function of healthy cattle
}

\author{
Sandra Satiko Kitamura ${ }^{\mathrm{I}}$ Enrico Lippi Ortolani ${ }^{\mathrm{II}}$
}

RESUMO

Dezesseis bovinos hígidos foram utilizados para estudar o efeito de diferentes doses de furosemida sobre a função renal, com destaque na excreção urinária de água e de alguns eletrólitos. Os animais foram divididos aleatoriamente em quatro grupos iguais e submetidos aos seguintes tratamentos: Controle (10mL de salina isotônica); 1 ; 2 e 3mg de furosemida $\mathrm{kg}^{-1} \mathrm{PV}$ aplicados por via intravenosa. Nas quatro horas seguintes, foram coletados todo o volume urinário $e$ amostras de sangue a cada hora, para a determinação de vários índices urinários. A furosemida aumentou o volume urinário em média mais de quatro vezes, nas doses de 2 e 3mg $\mathrm{kg}^{-1}$, comparadas à de $1 \mathrm{mg} \mathrm{kg}^{-1}$, principalmente nas primeiras duas horas de ação. Não existiu diferença na taxa de filtração glomerular, mas uma marcante diminuição na reabsorção tubular de água e sódio e, em menor grau, de potássio, explicando a diurese. A osmolaridade decresceu cerca de $28 \%$ em todas as doses de furosemida. Os dados indicam que a melhor dose para promover efeitos diuréticos da furosemida em ruminantes deve ser a de $2 \mathrm{mg} \mathrm{kg}^{-1} \mathrm{PV}$.

Palavras-chave: furosemida, bovino, excreção urinária, eletrólitos.

\section{ABSTRACT}

To study the effects of different doses of furosemide on the urinary excretion of water and electrolytes 16 healthy steers were used. The animals were randomly divided into four groups and treated, intravenously, as follow: control $(10 \mathrm{~mL}$ of isotonic saline); $1 ; 2$ and $3 \mathrm{mg} \mathrm{kg}^{-1} \mathrm{BW}$ of furosemide. For the next $4 h$, the urinary volume was measured and blood samples were taken to calculate the urinary excretion ratio. Furosemide increased the urinary volume by four fold, with higher effect with 2 and $3 \mathrm{mg}$ than $1 \mathrm{mg}$, mainly in the $1^{\text {st }}$ and $2^{\text {nd }}$ hour of treatment. Furosemide did not change the glomerular filtration rate, but decreased significantly the tubular reabsortion of water, sodium, and at lower level of potassium, causing the diuresis. The osmolality was decreased about $28 \%$ in either doses of furosemide. For practical use $2 \mathrm{mg} \mathrm{kg}^{-1} \mathrm{BW}$ of furosemide should be adopted for diuretic effect in cattle.

Key words: furosemide, cattle, urinary excretion, electrolytes.

\section{INTRODUÇÃO}

A furosemida é o diurético mais utilizado no tratamento de edemas localizados ou generalizados em animais domésticos (QUAMME, 1986). O fármaco é amplamente utilizado na prática veterinária, devido a sua pronta atuação, alta capacidade de remoção de fluidos intersticiais, média toxicidade e rápida eliminação do organismo (ADAMS, 2003). É considerado um diurético de atuação na alça de Henle, em especial no ramo ascendente espesso. Além disso, sugere-se que a furosemida, além de atuar neste sítio, também interfere sobre o glomérulo renal, aumentando a sua capacidade de filtração em ratos (HOECHST, 1980). Porém, em seres humanos, tal fato não parece ocorrer (BRENNER, 1996). Por ausência de estudos, esta possível atuação da furosemida sobre o glomérulo renal ainda necessita ser avaliada em ruminantes.

A furosemida é secretada no lúmen do túbulo proximal dos néfrons e atua inibindo o

IDepartamento de Clínica Médica, Faculdade de Medicina Veterinária e Zooctenia, Universidade de São Paulo (FMVZ/USP), Universidade Anhembi Morumbi (UAM) e Universidade Paulista (UNIP), São Paulo, Brasil.

IIDepartamento de Clínica Médica (FMVZ/USP). Av. Prof. Dr. Orlando Marques de Paiva, 87, 05508-900, São Paulo, Brasil. Email: ortolani@usp.br. Autor para correspondência. 
cotransportador $\mathrm{Na}^{+}-\mathrm{K}^{+}-2 \mathrm{Cl}^{-}$, presente na membrana luminal do ramo ascendente grosso da alça de Henle, que é responsável pela reabsorção de cerca de 30\% do sódio no néfron (QUAMME, 1986), promovendo a retenção de potássio e cloreto no lúmen deste segmento, impedindo a manutenção da hiperosmolaridade do espaço intersticial entre os ramos descendente e ascendente da alça de Henle (ADAMS, 2003). Este evento impede a existência de um gradiente químico que favoreça a saída de água do ramo descendente da alça de Henle, que apresenta permeabilidade à água. Assim, a água que deveria ser reabsorvida no ramo descendente permanece no lúmen, desencadeando intensa diurese, resultante desse desbalanço do mecanismo contracorrente (QUAMME, 1986). O comprometimento da reabsorção de sódio determina que outros eletrólitos sejam também menos reabsorvidos, como é o caso do potássio, cálcio e magnésio (ADAMS, 2003).

A maioria dos trabalhos estudando o efeito da furosemida sobre a excreção de eletrólitos foi conduzida em animais de laboratório e no homem. No entanto, VESTWEBER et al. (1989) analisaram o efeito da furosemida (1mg kg-1 PV) no tratamento de vacas com edema mamário, acompanhando pontualmente a concentração de eletrólitos na urina. Porém, esses autores não avaliaram a excreção urinária global dessas substâncias, nem a influência de doses superiores de furosemida sobre o volume urinário.

A dosagem indicada de furosemida para bovinos varia de 0,5 a $1 \mathrm{mg} \mathrm{kg}^{-1} \mathrm{PV}$ (ADAMS, 2003), mas estudos da eliminação de eletrólitos pela urina com doses superiores a $1 \mathrm{mg} \mathrm{kg}^{-1} \mathrm{PV}$, analisando o volume urinário e a excreção global de eletrólitos, não foram realizados nesta espécie.

Os objetivos deste estudo foram verificar a influência da aplicação de diferentes doses de furosemida em bovinos hígidos sobre o volume urinário, a taxa de filtração glomerular, os índices de excreção urinária (IEU), fracional (IEF) e sobre a excreção global de sódio, potássio e uréia.

\section{MATERIAL E MÉTODOS}

Foram utilizados 16 bovinos mestiços machos, com cerca de $240 \mathrm{~kg}$ de peso vivo. Os animais receberam alimentação composta por $80 \%$ de feno de capim coast-cross e $20 \%$ de concentrado comercial, com $10 \%$ de proteína bruta, além de água e sal mineral comercial à vontade. A alimentação era oferecida uma única vez ao dia, às 7h, na quantidade de matéria seca correspondente a $2,5 \%$ do peso vivo.

Os animais foram alocados aleatoriamente em quatro grupos, com quatro animais cada. O primeiro grupo foi mantido como controle, recebendo $10 \mathrm{~mL}$ de solução salina isotônica por via intravenosa (IV). Os outros três foram medicados (IV) com 1, 2 ou 3mg de furosemida por kg/PV. O experimento se iniciava sempre às $10 \mathrm{~h}$ da manhã, sendo os bovinos acompanhados por 4 horas, período em que permaneciam sem acesso a água e ração.

Cerca de uma hora antes do início do ensaio, foi aderido, por meio de fita comercial (Silvertape ${ }^{\circledR}$ ) no prepúcio de cada um dos animais, um tubo cirúrgico flexível, de cerca de 1,5 metro de comprimento (Latex Altamira ${ }^{\circledR}$ ), que conduzia a urina para um frasco plástico para a obtenção do volume urinário. Momentos antes do início do experimento, eram obtidas amostras de urina para constituir o momento zero, por meio de estímulo na região prepucial, repetindo-se essas coletas na $1^{\underline{a}}, 2^{\underline{a}}, 3^{\underline{a}}$ e $4^{\underline{a}}$ horas após a aplicação dos medicamentos. Nesses momentos, eram obtidas, por venipunção, amostras de sangue da jugular em tubos a vácuo, sem presença de anticoagulante, para determinação de sódio, potássio, uréia e creatinina séricas. Além desses momentos, assim que o animal urinasse, era mensurado o volume de urina e uma amostra deste fluido era armazenada em alíquotas, a $20^{\circ} \mathrm{C}$, até a análise laboratorial. Imediatamente após as coletas, era mensurada a osmolaridade das amostras, em osmômetro (Modelo 3300 - Advanced ${ }^{\circledR}$ ) que avalia o ponto de congelamento. No laboratório, as amostras de urina eram descongeladas para a análise de creatinina e uréia pelas técnicas de LUTSGARTEN \& WENCK (1972) e TALKE \& SCHUBERT (1965) e de sódio e potássio pela fotometria de chama.

A taxa de filtração glomerular foi acompanhada no decorrer das quatro horas de experimento e calculada segundo fórmula descrita por FLEMING et al. (1991), utilizando-se a taxa de depuração da creatinina $\mathrm{C}_{\mathrm{cr}}=\left(\mathrm{U}_{\mathrm{cr}} / \mathrm{S}_{\mathrm{cr}}\right) \times \mathrm{V}$, em que $\mathrm{U}_{\mathrm{cr}}=$ concentração de creatinina urinária mmol/L, $\mathrm{S}_{\mathrm{cr}}$ concentração de creatinina sérica e $\mathrm{V}=$ quantidade de excreção de urina no período ( $\mathrm{mL}$ minuto ${ }^{-1} \mathrm{~kg}^{-1} \mathrm{PV}$ ).

Para avaliar a capacidade de depuração sangüínea de sódio, potássio e uréia sangüínea pelos rins, no decorrer do experimento, foi calculado o Índice de Excreção Fracional (IEF), segundo a fórmula descrita por FLEMING et al. (1991): $E F x=\left(U_{x} / S_{x}\right) X\left(S_{c r} X U_{c r}\right) X$ 100 , em que Ux é a concentração da substância na urina e $S_{x}$ a concentração da metabólito no soro. Para avaliar a capacidade global de excreção urinária, independentemente da diluição daqueles íons supracitados, foi calculado o Índice de Excreção Urinária (IEF): $\mathrm{U}_{\mathrm{x}} / \mathrm{U}_{\mathrm{cr}}$.

Foi aplicado o teste de Kolmogorov e Smirnov para se conhecer a distribuição dos dados 
das variáveis. Caso estas tivessem distribuição nãoparamétrica, eram comparadas entre si pelo Teste Kruskal-Wallis. Caso fossem paramétricas, as variáveis eram analisadas inicialmente pelo teste $\mathrm{F}$ e posteriormente comparadas pelo teste de Tukey, considerando-se nível de 5\% de significância. No estudo da relação entre duas variáveis, foi avaliado o coeficiente de correlação (LITTLE \& HILLS, 1978).

\section{RESULTADOS}

O efeito diurético teve seu início ao redor do $7^{\circ}$ o minuto e prolongou-se até a $2^{\underline{a}} \mathrm{~h}$, independentemente da dose utilizada. Os animais tratados com 2 e $3 \mathrm{mg} \mathrm{kg}^{-1}$ de furosemida tiveram maior volume global de urina que os medicados com $1 \mathrm{mg} \mathrm{kg}^{-1}$, os quais foram superiores ao grupo controle $(\mathrm{P}<0,0001)$ (Tabela 1). O volume de urina excretado, nos diferentes momentos do experimento, foi semelhante nos animaiscontrole $(\mathrm{P}>0,6)$; já nos três grupos medicados com furosemida, a excreção foi maior nas primeiras duas horas; apenas no grupo $3 \mathrm{mg} \mathrm{kg}^{-1} \mathrm{o}$ volume urinário foi menor na $4^{\mathrm{a}}$ que na $3^{\mathrm{a}}$ hora $(\mathrm{P}<0,0001)$ (Tabela 2$)$. Nas primeiras duas horas, o grupo controle excretou menos urina que os demais grupos. Já na $3^{\underline{a}}$ hora, o mesmo fato passou também a acorrer com o grupo $1 \mathrm{mg} \mathrm{kg}^{-1}$, enquanto que, na $4^{\mathrm{a}}$ hora, o grupo $2 \mathrm{mg} \mathrm{kg}^{-1}$ produziu mais urina que os demais tratamentos $(\mathrm{P}<0,0001)$ (Tabela 2). Não existiu diferença significativa na taxa de filtração glomerular (TFG) ( $\mathrm{mL} \mathrm{min}{ }^{-1} \mathrm{~kg}^{-1} \mathrm{PV}$ ) entre os tratamentos $(\mathrm{P}>0,3)$ (Tabela 1$)$.

Os teores médios $\left(\mathrm{mM} \mathrm{L}^{-1}\right)$ de uréia, creatinina e potássio urinários apresentaram maiores valores nos animais-controle que nos tratados com furosemida, que não exibiram diferença entre si. Contudo, fato inverso ocorreu com os teores médios de sódio urinário $(\mathrm{P}<0,0001)$ (Tabela 1$)$.

O quadro 1 apresenta os coeficientes de correlação e suas respectivas significâncias entre as variáveis estudadas. Todos os coeficientes foram significativos, mas um deles foi de baixa intensidade (Na X Osm), cinco deles de média intensidade $(0,3<\mathrm{r}<$ $0,6)$ e quatro de alta intensidade $(r>0,6)$, em especial quando se correlacionavam com a osmolaridade.

Todos os índices, tanto o fracional (IEF) quanto o de excreção (IEU) urinária de íons, tiveram distribuição não-paramétrica, sendo expressos em mediana, com exceção do índice de uréia, que está apresentado em média e desvio-padrão (Tabela 3). Tanto o IEF como o IEU do sódio foram superiores nos grupos medicados com furosemida em relação ao controle. Já esses dois índices do potássio foram maiores nos grupos 2 e $3 \mathrm{mg}$ que nos demais tratamentos $(\mathrm{P}<0,0001)$. O IEF da uréia foi maior no grupo $2 \mathrm{mg}$ que no controle $(\mathrm{P}<0,05)$. O IEU da uréia foi superior no grupo $2 \mathrm{mg}$ em relação aos grupos controle e $1 \mathrm{mg}$ de furosemida $(\mathrm{P}<0,004)$.

\section{DISCUSSÃO}

Como era de se esperar, a furosemida aumentou o volume global de urina, sendo que as doses de 2 e $3 \mathrm{mg} \mathrm{kg}^{-1}$ foram semelhantes entre si e superiores a $1 \mathrm{mg} \mathrm{kg}^{-1}$ (Tabela 1). Os idênticos resultados entre $2 \mathrm{e}$ $3 \mathrm{mg} \mathrm{kg}^{-1}$ sugerem que o uso de doses superiores de furosemida provavelmente não aumente a diurese, mas tal fato ainda precisa ser mais bem estudado. Esses resultados demonstram que as recomendações de dosagem de furosemida para bovinos precisam ser reavaliadas, pois doses superiores a $1 \mathrm{mg} \mathrm{kg}^{-1}$, apontadas como ideais por ADAMS (2003), promoveram maior diurese e depuração sangüínea de potássio (Tabela 1; 3). Por essas constatações e pelo fato de que, na 4 a h, à dose de $2 \mathrm{mg} \mathrm{kg}^{-1}$ continuou a ter ação diurética superior a de $3 \mathrm{mg} \mathrm{kg}^{-1}$, elegeu-se a dose de $2 \mathrm{mg} \mathrm{kg}^{-1}$, entre as estudadas, como a mais adequada para promover efeitos diuréticos com fins terapêuticos. Reforça esta sugestão do aumento de dose, de 1 para

Tabela 1 - Volume global, valores médios de taxa de filtração glomerular (TFG), osmolaridade e teores de uréia, creatinina, sódio e potássio urinários de bovinos tratados ou não com diferentes doses de furosemida, no decorrer de 4 horas.

\begin{tabular}{|c|c|c|c|c|c|c|c|}
\hline & $\begin{array}{l}\text { Volume global } \\
\text { (L) }\end{array}$ & 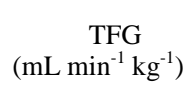 & $\begin{array}{l}\text { Osmolaridade } \\
\left(\mathrm{mOsm} \mathrm{L}^{-1}\right)\end{array}$ & $\begin{array}{l}\text { Uréia urinária } \\
\left(\mathrm{mM} \mathrm{L}^{-1}\right)\end{array}$ & $\begin{array}{l}\text { Creatinina } \\
\text { urinária } \\
\left(\mathrm{mM} \mathrm{L}^{-1}\right)\end{array}$ & $\begin{array}{l}\text { Sódio urinário } \\
\quad\left(\mathrm{mM} \mathrm{L}^{-1}\right)\end{array}$ & $\begin{array}{l}\text { Potássio } \\
\text { urinário } \\
\left(\mathrm{mM} \mathrm{L}^{-1}\right)\end{array}$ \\
\hline Controle & $2,56 \pm 1,23^{c}$ & $0,87 \pm 0,27^{\mathrm{a}}$ & $424 \pm 129^{a}$ & $184,9 \pm 96,7^{\mathrm{a}}$ & $3,98 \pm 1,81^{a}$ & $36,4 \pm 25,6^{b}$ & $91,2 \pm 36,9^{a}$ \\
\hline $1 \mathrm{mg}$ & $9,71 \pm 1,34^{\mathrm{b}}$ & $1,4 \pm 0,32^{a}$ & $314 \pm 100^{b}$ & $64,7 \pm 42,4^{b}$ & $1,72 \pm 1,47^{\mathrm{b}}$ & $83,0 \pm 32,0^{a}$ & $49,7 \pm 20,8^{b}$ \\
\hline $2 \mathrm{mg}$ & $13,93 \pm 2,38^{a}$ & $1,05 \pm 0,52^{\mathrm{a}}$ & $305 \pm 69^{b}$ & $58,9 \pm 51,3^{b}$ & $0,98 \pm 1,11^{b}$ & $90,5 \pm 24,9^{\mathrm{a}}$ & $49,3 \pm 27,0^{b}$ \\
\hline $3 m g$ & $13,33 \pm 0,96^{a}$ & $1,08 \pm 0,42^{a}$ & $299 \pm 56^{b}$ & $37,9 \pm 22,7^{b}$ & $1,02 \pm 1,04^{b}$ & $78,6 \pm 15,8^{a}$ & $54,1 \pm 27,8^{b}$ \\
\hline Significância & $\mathrm{P}<0,0001$ & $\mathrm{P}>0,3$ & $\mathrm{P}<0,0001$ & $\mathrm{P}<0,0001$ & $\mathrm{P}<0,0001$ & $\mathrm{P}<0,0001$ & $\mathrm{P}<0,0001$ \\
\hline
\end{tabular}

Letras minúsculas distintas na mesma coluna indicam diferença significativa entre os grupos.

Ciência Rural, v.37, n.5, set-out, 2007. 
Tabela 2 - Volume urinário (em L) excretado pelos animais nos diferentes tratamentos e momentos do experimento.

\begin{tabular}{|c|c|c|c|c|}
\hline & 1 hora & 2 horas & 3 horas & 4 horas \\
\hline Controle & $0,8 \pm 0,3^{\mathrm{Ab}}$ & $0,68 \pm 0,3^{\mathrm{Ab}}$ & $0,63 \pm 0,5^{\mathrm{Ab}}$ & $0,53 \pm 0,2^{\mathrm{Ab}}$ \\
\hline $1 \mathrm{mg}$ & $4,82 \pm 1,1^{\mathrm{Aa}}$ & $3,35 \pm 0,4^{\mathrm{Aa}}$ & $1,0 \pm 0,4^{\mathrm{Bb}}$ & $0,56 \pm 0,5^{\mathrm{Bb}}$ \\
\hline $2 \mathrm{mg}$ & $5,9 \pm 0,9^{\mathrm{Aa}}$ & $4,4 \pm 0,6^{\mathrm{Aa}}$ & $2,42 \pm 1,1^{\mathrm{Ba}}$ & $1,27 \pm 0,5^{\mathrm{Ba}}$ \\
\hline $3 \mathrm{mg}$ & $6,6 \pm 0,9^{\text {Аа }}$ & $4,32 \pm 0,5^{\mathrm{Aa}}$ & $1,74 \pm 0,8^{\mathrm{Ba}}$ & $0,7 \pm 0,9^{\mathrm{Cb}}$ \\
\hline
\end{tabular}

Letras maiúsculas distintas na mesma linha indicam diferença significativa dentro do grupo (P<0,0001).

Letras minúsculas distintas na mesma coluna indicam diferença significativa entre os grupos $(\mathrm{P}<0,0001)$.

$2 \mathrm{mg} \mathrm{kg}^{-1} \mathrm{PV}$, a constatação de SHAIKH et al. (2002), feita em vacas lactentes, que parte significativa da furosemida aplicada na quantidade de $1 \mathrm{mg} \mathrm{kg}^{-1} \mathrm{PV}$ foi excretada pela glândula mamária, nas primeiras 10 horas após o tratamento, reduzindo rapidamente sua concentração sérica e diminuindo assim sua ação.

Em relação ao efeito diurético da furosemida, constatou-se que o medicamento aplicado por via intravenosa atuava já no 7ํㅡinuto, independentemente da dose aplicada, fato semelhante ao descrito por VESTWEBER et al. (1989). Contudo, no presente experimento, o efeito do diurético, analisado pelo volume urinário, foi máximo nas primeiras duas horas, decaindo progressivamente nas horas seguintes, fato diferente do descrito por QUAMME (1986) em monogástricos, cuja ação da furosemida é máxima até a $3^{\text {a }}$ hora de aplicação.

Segundo os resultados obtidos no presente experimento, o aumento do volume urinário pela ação da furosemida não se deu por elevação na taxa de filtração glomerular, como fora descrita anteriormente em ratos (HOECHST, 1980), já que não existiu diferença entre o grupo controle e os medicados. Os presentes resultados são semelhantes aos avaliados em seres humanos, que também constataram ausência de alteração na taxa de filtração glomerular (BRENNER, 1996). A falta de atuação da furosemida nos glomérulos está ligada ao seu metabolismo, pois, na corrente sangüínea, liga-se fortemente às proteínas séricas, sendo um terço dela eliminado intacto pela bile e o restante secretado livre nos túbulos contorcidos proximais, atuando por contato nas células da parede da alça de Henle, sem ter acesso aos glomérulos (QUAMME, 1986; ADAMS, 2003).

Os valores de taxa de filtração glomerular encontrados nos bovinos medicados (Tabela 1) ou não com furosemida se encontram dentro dos considerados normais descritos na literatura $(0,38$ a 1,74mL $\mathrm{min}^{-1} \mathrm{~kg}^{-1} \mathrm{PV}$ ) (FLEMING et al., 1991).

A furosemida é conhecida por sua ação nos túbulos renais, em especial na alça ascendente de Henle, daí ser denominada de "diurético de alça” (BRENNER, 1996). O aumento do volume urinário se dá como decorrência da menor reabsorção tubular de sódio, já que este eletrólito é bastante reabsorvido neste segmento tubular. Esta maior presença de sódio no lúmen provoca grande retenção de água no interior do túbulo, gerando a diurese (QUAMME, 1986). De fato, no presente experimento o índice de excreção urinária de sódio chegou a ser onze vezes maior nos

Quadro 1 - Coeficientes de correlação e suas significâncias entre as variáveis urinárias estudadas.

\begin{tabular}{|c|c|c|c|c|}
\hline & $\begin{array}{l}\text { Uréia urinária } \\
\left(\mathrm{mM} \mathrm{L}^{-1}\right)\end{array}$ & $\begin{array}{l}\text { Creatinina urinária } \\
\qquad\left(\mathrm{mM} \mathrm{L}^{-1}\right)\end{array}$ & $\begin{array}{l}\text { Sódio urinário } \\
\quad\left(\mathrm{mM} \mathrm{L}^{-1}\right)\end{array}$ & $\begin{array}{l}\text { Potássio urinário } \\
\left(\mathrm{mM} \mathrm{L} \mathrm{L}^{-1}\right)\end{array}$ \\
\hline \multirow{2}{*}{ Osmolaridade (mOsm L ${ }^{-1}$ ) } & $\mathrm{r}=+0,80$ & $r=+0,89$ & $r=+0,28$ & $\mathrm{r}=+0,90$ \\
\hline & $\mathrm{P}<0,0001$ & $\mathrm{P}<0,0001$ & $\mathrm{P}<0,02$ & $\mathrm{P}<0,0001$ \\
\hline \multirow{2}{*}{ Uréia urinária $\left(\mathrm{mM} \mathrm{L}^{-1}\right)$} & \multirow{2}{*}{-} & $r=+0,86$ & $r=-0,51$ & $r=+0,47$ \\
\hline & & $\mathrm{P}<0,0001$ & $\mathrm{P}<0,0001$ & $\mathrm{P}<0,0001$ \\
\hline \multirow{2}{*}{ Creatinina urinária $\left(\mathrm{mM} \mathrm{L}^{-1}\right)$} & \multirow{2}{*}{-} & \multirow{2}{*}{-} & $r=-0,54$ & $r=+0,54$ \\
\hline & & & $\mathrm{P}<0,0001$ & $\mathrm{P}<0,0001$ \\
\hline \multirow{2}{*}{ Sódio urinário $\left(\mathrm{mM} \mathrm{L}^{-1}\right)$} & \multirow{2}{*}{-} & \multirow{2}{*}{-} & \multirow{2}{*}{-} & $r=-0,43$ \\
\hline & & & & $\mathrm{P}<0,0001$ \\
\hline
\end{tabular}

Ciência Rural, v.37, n.5, set-out, 2007. 
Tabela 3 - Valores dos índices de excreção fracional (IEF) de sódio, de potássio, uréia urinária (\%) e índice de excreção urinária (IEU) de sódio, potássio, uréia (mM) nas diferentes doses de furosemida estudadas.

\begin{tabular}{|c|c|c|c|c|c|c|}
\hline & & Controle & $1 \mathrm{mg}$ & $2 \mathrm{mg}$ & $3 \mathrm{mg}$ & Signif \\
\hline \multirow{3}{*}{ IEF (\%) } & Sódio & $1,2^{b}$ & $5,5^{a}$ & $13,0^{\mathrm{a}}$ & $9,3^{\mathrm{a}}$ & $\mathrm{P}<0,0001$ \\
\hline & Potássio & $97,1^{\mathrm{b}}$ & $166,4^{\mathrm{b}}$ & $303,3^{a}$ & $261,1^{\mathrm{a}}$ & $\mathrm{P}<0,0001$ \\
\hline & Uréia & $103 \pm 27^{b}$ & $138 \pm 48^{\mathrm{ab}}$ & $154 \pm 57^{\mathrm{a}}$ & $139 \pm 57^{a b}$ & $\mathrm{P}<0,05$ \\
\hline \multirow{3}{*}{ IEU (mM) } & Sódio & $6,7^{\mathrm{b}}$ & $27,1^{\mathrm{a}}$ & $74,2^{a}$ & $39,7^{\mathrm{a}}$ & $\mathrm{P}<0,0001$ \\
\hline & Potássio & $28,2^{b}$ & $41,9^{\mathrm{b}}$ & $61,4^{\mathrm{a}}$ & $61,1^{\mathrm{a}}$ & $\mathrm{P}<0,0001$ \\
\hline & Uréia & $49 \pm 25^{b}$ & $48 \pm 20^{b}$ & $74 \pm 30^{\mathrm{a}}$ & $53 \pm 25^{a b}$ & $\mathrm{P}<0,004$ \\
\hline
\end{tabular}

Letras distintas na mesma linha indicam diferença significativa entre os grupos.

animais tratados com $2 \mathrm{mg} \mathrm{kg}^{-1}$ de furosemida, em relação ao controle. Os altos teores de sódio na urina provocaram queda nas concentrações de creatinina $(r=-0,54)$, indicando maior diluição do soluto urinário.

Em relação ao potássio, detectou-se aumento tanto no índices de excreção urinária como no fracional nos grupos que receberam 2 e $3 \mathrm{mg} \mathrm{kg}^{-1}$ de furosemida (Tabela 3). Segundo QUAMME (1986), a falta de reabsorção do sódio no túbulo ascendente da alça de Henle faz com que outros eletrólitos, tais como potássio, cálcio e magnésio, também sejam menos reabsorvidos para o interstício. É interessante ressaltar que este efeito para o potássio foi dose-dependente, já não ocorrendo o mesmo para o sódio, que foi sempre superior ao grupo controle, mesmo na dose de $1 \mathrm{mg} \mathrm{kg}^{-1}$ de furosemida (Tabela 3). Duas hipóteses foram levantadas: ou a quantidade de sódio no filtrado nesse segmento foi menor com o uso de $1 \mathrm{mg} \mathrm{kg}^{-1}$, possibilitando alguma reabsorção de potássio para o interstício, ou uma maior quantidade de furosemida "per se" evitou a reabsorção de potássio. Esses resultados contrariam as afirmações de BRENNER (1996) de que a furosemida não interfere na excreção de potássio pela urina.

Embora a maior excreção de sódio promova também maior eliminação de potássio, foi constatada no presente experimento uma correlação negativa $(r=-0,43$; $\mathrm{P}<0,0001)$ entre estes eletrólitos na urina. À primeira vista, este resultado indica certa contradição, mas o mesmo pode ser explicado pela magnitude de excreção desses macroelementos na urina. Enquanto os teores de sódio por litro de urina elevaram-se ao redor de 2,5 vezes, os de potássio diminuíram quase duas vezes (Tabela 1). Essa aparente diminuição da excreção de potássio é desfeita pelo aumento, em mais de $100 \%$, que as doses altas de furosemida provocaram no IEU deste eletrólito (Tabela 3). É importante relembrar que esse índice é corrigido pela concentração de creatinina. Em outras palavras, embora os teores de creatinina tenham diminuído cerca de quatro vezes em animais medicados com 2 e $3 \mathrm{mg} \mathrm{kg}^{-1}$ de furosemida, os de potássio só decresceram menos de duas vezes (Tabela 1), implicando que a excreção de potássio tenha aumentado mais de duas vezes, como revelou o IEU (Tabela 3). Como os teores de creatinina e potássio foram decrescidos semelhantemente na urina, embora em porcentagens diferentes, existiu correlação positiva entre estas substâncias $(r=+0,54)$.

A osmolaridade urinária foi significativamente reduzida em média $120 \mathrm{mOsm} \mathrm{L}^{-1}$, ou cerca de $28 \%$, pela furosemida, indicando que a urina se tornou mais diluída (Tabela 1). Isso ficou comprovado com a franca diminuição da creatinina urinária, que apresentou altíssima correlação com a osmolaridade neste fluido $(r=+0,89)$. Na urina de bovino normal, cerca de $40 \%$ da osmolaridade é fornecida pela excreção de uréia, vindo em seguida o potássio e o sódio (SWENSON \& REECE, 1996). Se, de um lado, a concentração de sódio em bovinos tratados com furosemida se elevou em torno de $47 \mathrm{mOsm} \mathrm{L}^{-1}$, a de potássio foi diminuída em semelhante quantidade (40 mOsm/L) (Tabela 1). Com este aparente equilíbrio, passou a ser determinante para a queda da osmolaridade urinária a reduzida excreção de uréia (-130mOsm L ${ }^{-1}$ ) (Tabela 1), concomitantemente com a maior excreção de água, visto que existiu alta correlação entre uréia e osmolaridade $(r=+0,80)$. Segundo BRENNER (1996), a furosemida não interfere com a reabsorção ou excreção tubular da uréia, indicando que a queda na concentração de uréia urinária (Tabela 1) foi decorrente da maior diluição da urina, constatada pela alta correlação uréia e creatinina urinária $(\mathrm{r}=+0,86)$.

\section{CONCLUSÕES}

Pode-se concluir que o efeito diurético da furosemida não ocorreu por meio de maior filtração glomerular, mas sim pela menor reabsorção tubular da água e dos eletrólitos. Como a dose de $2 \mathrm{mg}$ foi idêntica à de $3 \mathrm{mg}$, mas superior à de 1mg, elegeu-se a quantidade 
de $2 \mathrm{mg} \mathrm{kg}^{-1} \mathrm{PV}$ como a ideal para promover efeitos diuréticos em bovinos. Além de aumentar a diurese, doses maiores de furosemida incrementaram grandemente a excreção de sódio e potássio. A diurese foi acompanhada da diminuição da osmolaridade da urina, provocada pela maior excreção de água, a despeito do aumento de excreção de sódio e potássio.

\section{AGRADECIMENTOS}

Ao Conselho Nacional de Desenvolvimento Científico e Tecnológico (CNPq), pela concessão de auxílio pesquisa. Às técnicas Clara Satsuki Mori e Marly Elizabeth Castro Ferreira, pelo apoio na realização das análises das amostras. Às médicas veterinárias Érica Minematsu e Karina Médici Madureira, pela colaboração durante a execução deste experimento. À Professora Doutora Mônica Akemi Sato, pelas importantes sugestões concernentes à discussão dos resultados.

\section{REFERÊNCIAS}

ADAMS, H.R. Farmacologia e terapêutica em veterinária. 8.ed. Rio de Janeiro: Guanabara Koogan, 2003. 1034p.

BRENNER, B.M. The kidney. 5.ed. Philadelphia: Saunders, 1996. 2702p.

FLEMING, S.A. et al. Renal clearance and fractional of electrolytes over four 6-hour periods in cattle. American
Journal of Veterinary Research, v.52, n.1, p.5-8, 1991.

HOECHST. Lasix ${ }^{\circledR}$ para uso veterinário. Informacion detallada sobre el producto. [S. l.]: HOECHST, 1980. 19p.

LITTLE, T.M.; HILLS, F.J. Agricultural experimentation: design and analysis. New York: John Wiley. 1978. 350p.

LUTSGARTEN, J.A.; WENK, R.E. Simple, rapid, kinetic method for serum creatinine measurement. Clinical Chemistry, v.18, p.1419-1422, 1972.

QUAMME, G.A. Loop diuretics. In: DIRKS, J.H.; SUTTON, R.A.L. Diuretics: physiology, pharmacology and clinical use. Philadelphia: Saunders, 1986. Cap.5, p.86-116.

SHAIKH, B. et al. Depletion of residues of furosemide, a loop diuretic, in lactating dairy cows. Journal of Veterinary Pharmacology and Therapeutics, v.25, n.5, p.387-388, 2002.

SWENSON, M.J.; REECE, W.O. Dukes/Fisiologia dos animais domésticos. 11.ed . Rio de Janeiro: Guanabara Koogan, 1996. 856p.

TALKE, H.; SCHUBERT, G.E. Enzymatische harnstoffbestimmung in blut und serum in optishen test nach warburb. Klinische Wochenschrift, v.43, n.174, p.174-175, 1965.

VESTWEBER, J.G.E. et al. Udder edema in cattle: effects of diuretics (furosemide, hydrochlorothiazide, acetazolamide, and $50 \%$ dextrose) on serum and urine electrolytes. American Journal of Veterinary Research, v.50, n.8, p.1323-1328, 1989. 